\title{
Duodenal biopsies in coeliac disease and non coeliac gluten sensitivity, with negative immune serology. A series of three cases
}

\begin{abstract}
Describe a series of three cases in which gluten intolerance is suspected; two of them with CD (Marsh 3B, negative IgA anti-TGt and IgA anti-DGP and positive IgG anti-DGP) and one with NCGS (negative IgA anti-TGt, IgA anti-GDP, IgE-WA and HLA-DQ2 and HLA-DQ8, and positive IgG anti-GDP). EDB confirmed CD by Marsh classification $3 \mathrm{~B}$, and NCGS in case 3 with Marsh 1.
\end{abstract}

Keywords: gluten intolerance, coeliac disease, IgE wheat allergy, IgG anti-gliadin, IgA anti-tissue trans-glutaminase antibodies, non coeliac gluten sensitivity, endoscopic duodenal biopsies, gluten diet, gluten free diet
Volume 4 Issue 3 - 2018

\author{
Elizondo-Vázquez Jorge Bernardo,' García- \\ Salazar Roberto, ${ }^{2}$ Guerrero-González José \\ Gerardo, ${ }^{2}$ Castro-Morales $\mathrm{H}^{3}$ \\ 'Pediatric gastroenterologist, Del Valle de México University, \\ México \\ ${ }^{2}$ Del Valle de México University, México \\ ${ }^{3}$ Pathologist, San José Hospital, México
}

\begin{abstract}
Correspondence: Elizondo-Vázquez Jorge Bernardo, Pediatric gastroenterologist, Gastroenterology teacher in Del Valle de México University, Campus, Hermosillo, Sonora, México, Tel 52(662)1900947, Email jelizondovazquez@gmail.com
\end{abstract}

Received: November 15, 2017 | Published: May 09, 2018 abdominal circumference of $98 \mathrm{~cm}$. After two weeks on GFD, facial and legs edema disappeared and abdominal circumference diminished to $77 \mathrm{~cm}(21 \mathrm{~cm})$.

ii. 36 year old female, her symptoms are since 19 years old: diarrhea, bloating and abdominal pain during and after meals. These symptoms disappeared after two weeks on GFD.

iii. 12 year old boy, with chronic constipation since first months of life, his bowel movements are one every 10 to 14 days, feces frequently stuck the toilet, he has excessive strain and time during defecation (30 to 60 minutes); sometimes, he has bloody striae in feces with bowel movements. After one week on GFD, the bowel movements changed since every 10 to 14 days, to one to three per day, without strain and pain and without laxatives. The time during bowel movements diminished from 30-60 to less than 10 minutes.

\section{Discussion}

We report three patients with suspected gluten intolerance; cases 1 and 2 have negative IgA anti-TGt and IgA anti-DGP and positive IgG anti-DGP; duodenal biopsies are Marsh 3b. ${ }^{9}$ Only case 2 has positive HLA-DQ8 haplotype, case 1 was not done (Figure 1) (Table 1).

Case 3 is a NCGS in which chronic constipation disappeared while on GFD for one week. IgA anti-TGt and IgA anti-DGP are negative, IgG anti-DGP is positive, and has Marsh 1 on duodenal biopsies; he also has negative HLA-DQ2 and HLA-Q8.

By clinical findings, the correct diagnosis of CD and NCGS cannot be done. $\mathrm{CD}$, cases one and two, have chronic bloating and abdominal pain; case one has facial and legs edema; and case two, has chronic diarrhea. The correct diagnosis has to be made by serologic markers (IgA anti-TGt and IgA anti-DGP) when there is no IgA deficiency, and when, they are negative, duodenal biopsies have to be done to confirm or rule out $\mathrm{CD}$. \section{associated with facial and legs edema; her symptoms improved with GFD, and worsen when she eats gluten. Although she runs seven kilometers a day, bloating is permanent and maintains an \\ Cases \\ i. Female developed, since 13 through 17 years old, and maintains an abdominal circumference of $98 \mathrm{~cm}$ and abdominal pain}


Table I Sex, age, symptoms, immunology tests, pathology findings and haplotypes

\begin{tabular}{|c|c|c|c|c|c|c|c|c|c|}
\hline \multirow[b]{2}{*}{ Case } & \multirow[b]{2}{*}{ Gender } & \multirow[b]{2}{*}{$\begin{array}{l}\text { Age } \\
\text { Years }\end{array}$} & \multirow[b]{2}{*}{ Symptoms } & \multicolumn{3}{|c|}{ CD antibodies } & \multirow{2}{*}{$\begin{array}{l}\text { Pathology } \\
\text { Marsh } \\
\text { Classification } \\
\end{array}$} & \multirow{2}{*}{$\begin{array}{l}\text { Haplotypes } \\
\text { HLA-DQ2 } \\
\text { HLA-DQ8 }\end{array}$} & \multirow[t]{2}{*}{ IgE-W } \\
\hline & & & & $\begin{array}{l}\text { IgG } \\
\text { anti-Gd }\end{array}$ & $\begin{array}{l}\text { IgA } \\
\text { anti-Gd }\end{array}$ & IgA antiTGt & & & \\
\hline 1 & Female & 17 & $\begin{array}{l}\text { Bloating, abdominal pain, } \\
\text { facial and legs edema }\end{array}$ & Positive & Negative & Negative & $3 b$ & Not done & Not done \\
\hline 2 & Female & 36 & $\begin{array}{l}\text { Bloating, abdominal pain, } \\
\text { chronic diarrhea }\end{array}$ & Positive & Negative & Negative & $3 b$ & HLA-DQ8 & Neg. \\
\hline 3 & Male & 12 & $\begin{array}{l}\text { Chronic constipation, } \\
\text { excesive strain and pain, } \\
\text { bloody striae during bowel } \\
\text { movements }\end{array}$ & Positive & Negative & Negative & 1 & Negative & Neg. \\
\hline
\end{tabular}

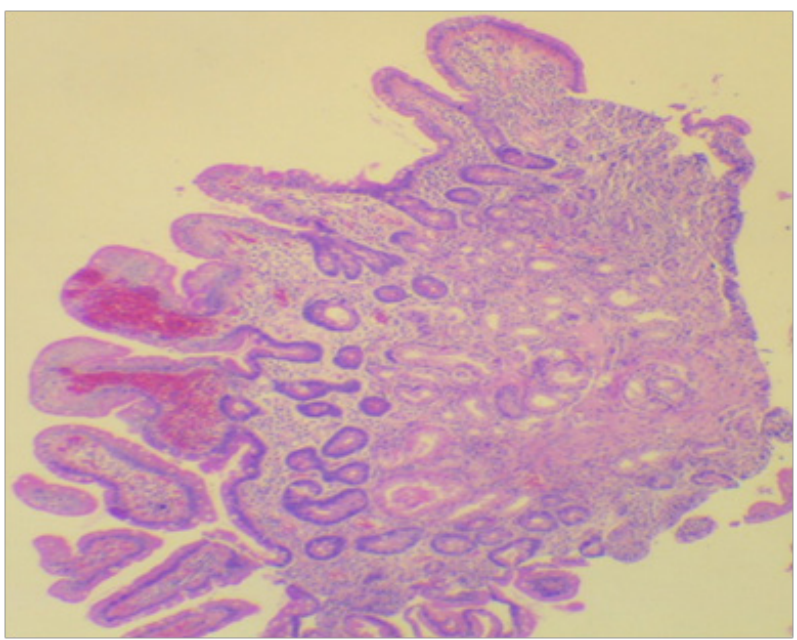

Figure I Pathology results in case 2. Coeliac disease. Small duodenal biopsy in case 2. Panoramic view of endoscopy duodenal biopsies with height shortening and widening of some duodenal villi. Lamina propria with lymphocites and plasmatic cells. Marsh 3B.

Case three has chronic constipation, it did no resolved with diet neither laxatives, since first months of age through 12 years old, constipation remitted in one week when he begins GFD, his bowel habits changed, from one every 10 to 14 days, to one to three per day, without straining, pain and neither laxative; it takes him less than 10 minutes, after a follow up of six months, he has not relapsed, does not has any bloody striae in feces and do not stuck them on toilet. Duodenal biopsies demonstrate slight chronic inflammatory cells on lamina propria, with normal villi, Marsh 1. CD is rule out by abscence of HLA-DQ2 and HLA-DQ8 haplotypes (Figure 2).

When physicians think their patients could have GI, because they have chronic digestive symptoms: diarrhoea, constipation, bloating, abdominal pain; or extra-intestinal: migraine, recurrent mouth ulcers, enamel defects, chronic dermatitis, herpetiform dermatitis, metabolic bone disease, arthralgias, arthritis, refractary anemia to iron, vit B12 or folic acid, ataxia, epileptic convultions, depression, first degree relative with $\mathrm{CD}$ or auto-immune disease, they have to continue looking for $\mathrm{CD}$, in first instance with serological biomarkers, followed by endoscopic duodenal biopsies.

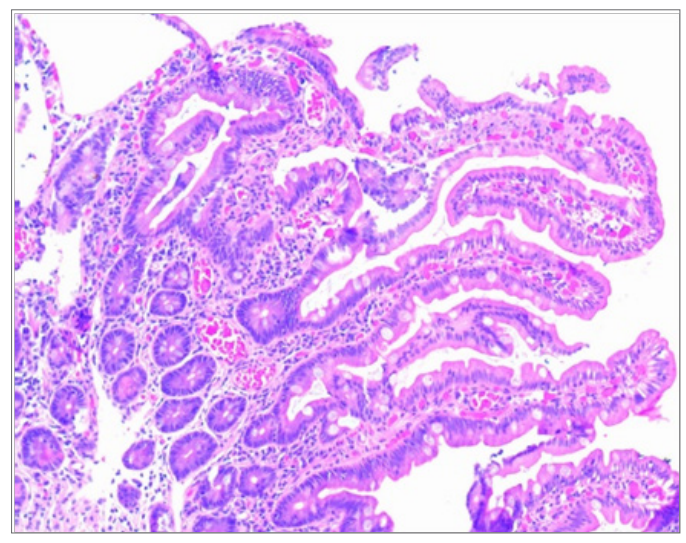

Figure 2 NCGS. Case 3. Duodenal mucosa with digit form villi, with cilindric epithelium and normal brush border. Lamina propia inflammation is slight to moderate, formed by lymphocites and plasmatic cells. Marsh I.

When IgA anti-TGt and IgA anti-DGP are negative, duodenal biopsies Marsh 2, 3 or 4 confirm CD; or rule out with Marsh 0; but if biopsies are Marsh 1, the haplotyes have the major importance, since if they are negative, CD is rule out and NCGS is confirmed. When IgA anti-TGt and IgA anti-DGP are negative and has positive IgG anti-DGP, in a suspected patient, with Marsh 0 or 1, and with negative HLA-Q2 and HLA.DQ8, the diagnosis is NCGS so, the next step, is follow the patient with GFD for one year and revalorate with new tests. What is known:

a. CD is an immune disease with genetic relation to HLA haplotpes, HLA-DQ2 and DQ8.

b. NCGS has been described in last four decades, and has not diagnostic serologic marker; in 2012, in a series, IgG anti-DGP is elevated in $56 \%$ of them.

c. CD can be Marsh 1 to 4, NGCD can be 0 or 1 .

\section{What should be known for clinical practitioners}

\section{Gl exists in three different settings}

i. CD: $\mathrm{CD}$ is $1 \%$ of population. Genetic backgrounds related to HLA leucocyte, DQ2 and DQ8 classes. Is for life once the diagnosis is made, the only efficient treatment is GFD for life. 
ii. NCGS: NCGS is an emergent entity, which produces digestive and extra-digestive symptoms when gluten is ingested; symptoms disappeared shortly after on GFD, and relapsed when are on GD. IgG anti-G is elevated in approximately $50 \%$, and duodenal mucosal biopsies are Marsh 0 or 1 . It can be six times more frequent than $\mathrm{CD}$. Non-coeliac gluten or wheat protein sensitivity is a syndrome characterized by both gastrointestinal and extraintestinal symptoms related to the ingestion of gluten and possibly other wheat proteins in people who do not have coeliac disease or wheat allergy recognized by diagnostic tests. ${ }^{12}$

iii. WA: Allergy to wheat is related to an elevated $\operatorname{IgE}$ to wheat. It occurs on $0.1 \%$ of population.

\section{Acknowledgments}

None.

\section{Conflict of interest}

Author declared that there is no conflict of interest.

\section{References}

1. Ludvigsson JF, Leffler DA, et al. The Oslo definitions for coeliac disease and related terms. Gut. 2013;62(1):43-52.

2. Rostom A, Murray JA, Kagnoff MF. American Gastroenterological Association (AGA) Institute Technical Review on the Diagnosis and Management of Celiac Disease. Gastroenterology. 2006;131(6):19812002.
3. Green PH, Jabri B. Coeliac disease. Lancet. 2003;362(9381):383-391.

4. Maglio M, Florian F, Vecchiet M, et al. Majority of children with type 1 diabetes produce and deposit anti-tissue transglutaminase antibodies in the small intestine. Diabetes. 2009;58(7):1578-1584.

5. Jamma S, Rubio-Tapia A, Kelly CP, et al. Celiac Crisis Is a Rare but Serious Complication of Celiac Disease in Adults. Clin Gastroenterol Hepatol. 2010;8(7):587-590.

6. Dieterich W, Laag E, Shoppers H, et al. Autoantibodies to tissue transglutaminase as predictors of celiac disease. Gastroenterology. 1998;115(6):1317-1321.

7. Pittschieler K, Ladinser B. Coeliac disease: screened by a new strategy. Acta Paediatr Suppl. 1996;412:42-45.

8. Ferguson A. Celiac disease, an eminently treatable condition, may be under diagnosed in the United States. Am J Gastroenterol. 1997;92(8):12521254.

9. Ciclitira PJ, King AL, Fraser JS. AGA technical review on celiac sprue: Am American Gastroenterological Association. Gastroenterology. 2001;120(6):1526-1540.

10. Mino M, Lauwers GY. Role of Lymphocytic Immunophenotyping in the Diagnosis of Gluten-Sensitive Enteropathy with Preserved Villous Architecture. Am J Surg Pathol. 2003;27(9):1237-1242.

11. Hoffmanová I, Sánchez D. Non-celiac gluten sensitivity. 2015;61(3):219-227.

12. Walker MM, Ludvigsson JF, Sanders DS. Coeliac disease: review of diagnosis and management. Med J Aust. 2017;21;207(4):173-178. 